\title{
La educación remota de emergencia y los peligros de imitar lo presencial
}

\author{
Ana Marotias ${ }^{1}$
}

Recibido: 10/12/2020; Aceptado: 20/12/2020

Cómo citar: Marotias, A. (2020 La educación remota de emergencia y los peligros de imitar lo presencial Revista Hipertextos, 8 (14), pp. 173-177. DOI: https://doi.org/10.24215/23143924e025

Resumen. Este texto ofrece algunas ideas respecto de los que aprendimos de las experiencias de un año signado por la pandemia y atravesado por las tecnologías digitales. A partir de una breve mirada sobre la Educación a Distancia (EAD) y la educación con Entornos Virtuales de Aprendizaje (EVEA) observa los riesgos del intento de imitar la presencialidad con el uso de determinadas teconlogías digitales.

Palabras clave: educación, pandemia, distancia, tecnologías digitales, entornos virtuales.

1 Doctora en Ciencias Sociales, Magíster en Ciencias Sociales y Educación y Licenciada en Ciencias de la Comunicación. Coordina el Programa de Educación Virtual de la Universidad Nacional de Rafaela (UNRaf) y dirige la Revista Hipertextos. Contacto: anamarotias@gmail.com 
Diciembre, mediodía, eclipse solar. Tarea inmediata: completar actas de exámenes llevados a cabo por videoconferencia. ¿Qué aprendimos de las experiencias de un año signado por la pandemia y atravesado por las tecnologías digitales? ¿Qué queda, qué se descarta, qué sigue en el ámbito de la educación superior?

En primer lugar, y aunque parezca obvio, el espacio áulico presencial es imposible de imitar. En muchas de las experiencias llevadas a cabo en la educación remota de emergencia, la videoconferencia, liderada por Zoom, intentó emular el aula. El resultado: casi todas las cámaras apagadas, interrupciones, ruidos, invitados sorpresa. Conocimos hijes, mascotas, parientes.

En muchos casos, y dependiendo de la habilidad didáctica del docente, se logró la participación de los estudiantes. En muchos otros, se dio un monólogo teórico usando recursos de alto consumo y condicionando al docente y a los estudiantes a la sincronicidad cuando el evento no lo ameritaba. Podría haberse resuelto con un audio, un video o una ficha teórica.

Esto no quiere decir que haya que dejar de usar la videoconferencia sino que, para aprovechar al máximo sus potencialidades, es necesario fijar objetivos didácticos claros a la hora de su utilización. Es decir: pensar qué particularidades tiene esa herramienta y centrar nuestras actividades en ellas. Sin dudas, su principal fuerte es la posibilidad de encontrarse de manera sincrónica, escucharse y verse. Por lo tanto, las actividades deberían ser interactivas y generar participación. Es decir, que cuando termine no nos quedemos pensando: "esto se podría haber resuelto con un video, un audio o un escrito".

Esta misma ventaja -la coincidencia espacio temporal- constituye una limitación: contar con un artefacto de uso exclusivo, una excelente conexión a Internet, un espacio privado y tranquilo para participar. Por lo tanto, las actividades que realicemos a través de videoconferencias no deberían ser obligatorias. Si bien el estudiante tenía destinado ese horario para asistir a clases presenciales, no necesariamente lo tiene disponible para conectarse desde su casa.

También aprendimos a usar los Entornos Virtuales de Aprendizaje (EVEA) que, salvo en las propuestas de Educación a Distancia Digital (Marotias, 2019), eran utilizados como repositorio y, a veces, para gestionar entregas de trabajos prácticos y/o exámenes.

De manera autodidacta, con capacitaciones brindadas por la institución, siguiendo tutoriales, compartiendo conocimiento entre pares, les profesores fuimos aprendiendo a utilizar diversas herramientas de estos entornos, con resultados muy variados.

Por otra parte, la ya clásica Educación a Distancia que, valiéndose de los medios de comunicación disponibles en cada época, media en el tiempo y en el espacio el vínculo pedagógico entre los integrantes de la propuesta educativa, intentó diferenciarse de esta educación remota de emergencia.

La característica principal de la Educación a Distancia (EAD) es la relación mediada a través de variados soportes (tanto analógicos como digitales) entre los protagonistas del proceso de enseñanza y de aprendizaje, sin co-presencia física y con mínima coincidencia temporal.

Siguiendo a Litwin (2000), la EAD es considerada como una modalidad educativa -no como un modelo unívoco- que adopta distintas características según las condiciones de los contextos en los que se desarrolla. Por otra parte, Marta Mena (2005) identifica como características centrales de la EAD la comunicación bidireccional y/o multidireccional entre los actores del proceso de enseñanza y aprendizaje; la accesibilidad para todas y todos los participantes; el diseño de materiales didácticos especialmente creados para la propuesta y la existencia de 
dispositivos de apoyo constante al estudiante. Estas condiciones mínimas deben darse en forma simultánea para que sea posible hablar de EAD.

Por lo tanto, lo que fuimos realizando durante 2020 no podría considerarse EAD: la videoconferencia intentó imitar las clases presenciales, echando por tierra la asincronicidad y con ello la posibilidad de organizar los propios tiempos de estudio de acuerdo con las posibilidades de conexión de los estudiantes; los profesores tuvieron que armar sus propios materiales educativos, cuando en una propuesta de EAD hay procesadores didácticos que se encargan de esta tarea; tampoco hubo tutores para realizar el seguimiento de los estudiantes, si bien, en algunos casos, algún integrante del equipo docente cumplió esta función.

La EAD tampoco es virtual. Pasó por diferentes etapas -correspondencia, radio, TV- por lo que no es posible subsumirla al uso de las tecnologías digitales y de Internet. Esto generaría un empobrecimiento del término al definir una propuesta de educación en función de los medios de transmisión utilizados, al mismo tiempo que provocaría una visión simplificada asumiendo únicamente una mirada tecnológica (Mena, 2005). Además, no es lo virtual lo que define a este tipo de educación, sino la modalidad a distancia, que encuentra en las tecnologías digitales la posibilidad de favorecer el encuentro entre pares, la relación con el tutor, o la construcción de materiales didácticos (Litwin, 2000: 26).

La EAD, tanto analógica como digital, es considerada como una alternativa democratizadora del acceso a la educación (Mena, 2004, 2005, 2011; Litwin, Maggio y Roig 1994, Litwin, 2000; Morelli, 2013), ya que permite que personas que por diversos motivos -etarios, laborales, familiares, geográficos, etc- no pueden cursar estudios de manera presencial, accedan a la educación.

Aquí es necesario tener en cuenta que una de las características que hacen que la EAD sea inclusiva, es la asincronicidad de la propuesta, al permitir que los estudiantes organicen sus tiempos de estudio en función de sus posibilidades. Por este motivo, es importante que la propuesta se centre en un Entorno Virtual de Enseñanza y Aprendizaje (EVEA) que constituya el espacio institucional para el vínculo educativo, donde se publiquen los materiales, se lleven a cabo los intercambios entre docentes y estudiantes, las actividades y las evaluaciones. Es decir, reservar los encuentros sincrónicos por videoconferencia para actividades que necesariamente requieran del intercambio sincrónico ya que, al exigir la coincidencia temporal, el consumo de una alta cantidad de recursos tecnológicos (conexión y artefactos adecuados), espacios físicos que garanticen tranquilidad para la participación, etc., resultan ser espacios excluyentes.

Otra cuestión que quedó al descubierto fue la creencia de que la educación presencial es de mejor calidad que la educación a distancia, como si fueran comparables. Por eso la necesidad de diferenciar a esta última de lo que se estuvo realizando en 2020 para mantener el vínculo pedagógico. También quedó de manifiesto la dificultad para dar clases de otra manera. Solo el hecho de decirle "clase" al encuentro sincrónico, y no a todo lo que se desarrolla en el EVEA, da cuenta de esa mirada.

El escenario educativo que se nos presentó en 2020 no representa todas las potencialidades de la educación a distancia, pero que no se pueda sostener una experiencia de EAD no quiere decir que lo presencial es mejor, o que la educación mediada por tecnologías digitales no sirve.

Como bien dicen Panico y Fernández: "Es cierto: la educación virtual nunca será como la presencial, ni debería esperarse que lo sea. Entre una y otra hay de lo común y de lo distinto. Lo que no deberíamos hacer es confundir las posibilidades de lo virtual, con nuestras posibilidades en lo virtual”' (Fernández y Panico, 2020). 
Aquí cabe detenerse, ya no en lo virtual o en lo presencial, sino en el vínculo pedagógico y didáctico en el ámbito de la educación superior. ¿Por qué seguimos pidiendo a nuestros estudiantes que lean para todas las clases si sabemos que la gran mayoría no lo va a hacer? ¿Por qué creemos que el que estudia todo junto antes del examen aprende menos que el ínfimo porcentaje que lo hace clase a clase? ¿Por qué la exposición del profesor no puede ser un punto de partida para la lectura? ¿Por qué tienen que escuchar la explicación después de haber leído? Si aún nos cuesta entender y adaptarnos a las características de nuestro estudiantado, es difícil poder hacer algo diferente cuando, además, cambian las reglas del juego.

Una fórmula que dio buen resultado durante la educación remota de emergencia fue publicar videos o audios del docente con las explicaciones teóricas, otros videos relacionados con la temática y actividades asincrónicas con devolución del docente. Dar un plazo relativamente largo (dos o tres semanas) para que los estudiantes lean, miren los videos, realicen las actividades en el EVEA y luego tener un encuentro sincrónico breve y no obligatorio con el objetivo de interactuar a través de actividades que generen la participación. De esa manera, los estudiantes pudieron organizar sus tiempos y empezar por donde les pareció más sencillo, de acuerdo con sus intereses y sus diversas formas de aprendizaje: el video o audio con la explicación, la bibliografía, los otros materiales, etc.

Además, asistimos a una sospecha alimentada a la sombra de la pandemia: lo virtual va a reemplazar al docente. En todo escenario educativo hay una concepción de la enseñanza y del aprendizaje, en lo virtual también y, por lo tanto, se necesita la intencionalidad pedagógica del docente, la elección de los contenidos, la moderación de los espacios de intercambio, la planificación y la corrección de las actividades. En síntesis, su participación, su voz (oral y/o escrita). No hay ausencia sino la posibilidad de construir otras y múltiples presencialidades.

Por otra parte, si bien a nivel técnico pueden duplicarse los contenidos en el EVEA para cada cohorte, cada grupo es diferente y la interacción que se da entre el docente y lo estudiantes moldea cada cursada. Es decir, no hay enlatado posible.

Este año dejó en evidencia que la educación va a incorporar lo virtual aun cuando se vuelva a lo presencial, por lo tanto, ni imitar lo presencial ni tratar de generar una propuesta de EAD clásica cuando la cursada no estaba prevista de esa manera, parece ser lo adecuado. La salida se vislumbra a través de la combinación entre la sincronía y la asincronía, alternando la utilización del EVEA con los encuentros presenciales o por videoconferencia, creando así un ámbito poderoso para la acción y la exploración, dándole a cada espacio el lugar adecuado de acuerdo con sus capacidades tecnológicas. Por supuesto que hay que tener en cuenta la desigualdad en los accesos y, además, luchar por conseguirlos.

Lo que queda claro es que los planteos binarios y la traducción lineal de lo presencial a lo virtual empobrecen y distorsionan. De lo que no hay dudas es del esfuerzo que hemos realizado para no resignar el derecho a la educación.

\section{Referencias}

Fernández, M. y Panico, B. (2020, 4 de mayo). Educación en cuarentena. La virtualidad bajo sospecha. Página 12. Recuperado de https://www.pagina12.com.ar/263760-educacion-encuarentena-la-virtualidad-bajo-sospecha 
Litwin, E. (2000). La educación a distancia. Temas para el debate en una nueva agenda educativa. Buenos Aires: Amorrortu.

Marotias, A. (2019). El rol de la Educación a Distancia en la universidad pública argentina (1986-2016). Tesis inédita de doctorado. Universidad de Buenos Aires, Buenos Aires.

Mena, M. (2004). La educación a distancia en América Latina. Modelos, tecnologías y realidades. Buenos Aires: La Crujía.

Mena, M. (Comp.) (2005). Construyendo la nueva agencia de la educación a distancia. Buenos Aires: La Crujía.

Mena, M. (2011). Políticas globales versus políticas regionales de educación a distancia. En 5to. Seminario Internacional de Educación a Distancia, De legados y horizontes para el siglo XXI. Veinte años de RUEDA. Tandil: Universidad Nacional del Centro de la Provincia de Buenos Aires.

Morelli, S. (2013). La distancia en la educación universitaria. En Copertari y Morelli (Comp.) Experiencias universitarias de enseñanzas a distancia (pp. 37-52). Rosario: Laborde. 